\title{
BMJ Open Impact of physician's sex/gender on processes of care, and clinical outcomes in cardiac operative care: a systematic review
}

\author{
Cole Etherington (D) , ${ }^{1,2}$ Mimi Deng, ${ }^{2}$ Sylvain Boet, ${ }^{1,2}$ Amy Johnston (D) ${ }^{3}$ \\ Fadi Mansour, ${ }^{2}$ Hussein Said, ${ }^{2}$ Katina Zheng (D) , ${ }^{4}$ Louise Y Sun (D) ${ }^{1,3,4,5}$
}

To cite: Etherington $\mathrm{C}$, Deng M, Boet S, et al. Impact of physician's sex/ gender on processes of care, and clinical outcomes in cardiac operative care: a systematic review. BMJ Open 2020;10:e037139. doi:10.1136/ bmjopen-2020-037139

- Prepublication history and additional material for this paper are available online. To view these files, please visit the journal online (http://dx.doi org/10.1136/bmjopen-2020037139).

Received 21 January 2020 Revised 30 July 2020 Accepted 14 August 2020

Check for updates

(c) Author(s) (or their employer(s)) 2020. Re-use permitted under CC BY-NC. No commercial re-use. See rights and permissions. Published by BMJ.

For numbered affiliations see end of article.

Correspondence to

Dr Louise Y Sun;

Isun@ottawaheart.ca

\section{ABSTRACT}

Objectives This systematic review aimed to assess the role of physician's sex and gender in relation to processes of care and/or clinical outcomes within the context of cardiac operative care.

Design A systematic review.

Data sources Searches were conducted in PsycINF0, Embase and Medline from inception to 6 September 2018. The reference lists of relevant systematic reviews and included studies were also searched.

Eligibility criteria for selecting studies Quantitative studies of any design were included if they were published in English or French, involved patients of any age undergoing a cardiac surgical procedure and specifically assessed differences in processes of care or clinical patient outcomes by physician's sex or gender. Studies were screened in duplicate by two pairs of independent reviewers.

Outcome measures Processes of care, patient morbidity and patient mortality.

Results The search yielded 2095 publications after duplicate removal, of which two were ultimately included. These studies involved various types of surgery, including cardiac. One study found that patients treated by female surgeons compared with male surgeons had a lower 30-day mortality. The other study, however, found no differences in patient outcomes by surgeon's sex. There were no studies that investigated anaesthesiologist's sex/gender. There were also no studies investing physician's sex or gender exclusively in the cardiac operating room.

Conclusions The limited data surrounding the impact of physician's sex/gender on the outcomes of cardiac surgery inhibits drawing a robust conclusion at this time. Results highlight the need for primary research to determine how these factors may influence cardiac operative practice, in order to optimise provider's performance and improve outcomes in this high-risk patient group.

\section{INTRODUCTION}

Approximately two million cardiac surgical procedures are performed globally every year. ${ }^{1}$ Complication rates after cardiac surgery vary from $2 \%$ to $60 \%$, depending
Strengths and limitations of this study

- This is the first systematic review to assess the impact of physician's sex and gender on patient outcomes in cardiac surgery.

- The robust search strategy and screening process identified two indirectly relevant articles, which included cardiac surgery as one of many specialties assessed.

- A potential limitation of this study is that only articles published in English or French were included; however, we address two potentially relevant studies published in other languages in our discussion.

- Findings highlight an important knowledge gap related to physician's sex/gender in the cardiac operating room, and in particular, as it relates to anaesthesiologists' practice as the included studies, only studied surgeons.

on the outcome examined. ${ }^{2-6}$ Importantly, many of these complications are preventable, and are related to ineffective teamwork in the operating room (OR). ${ }^{7-16}$ Effective teamwork encompasses both observable behaviours and clinicians' perceptions of interpersonal processes. ${ }^{17}$ 18 Though all team members play an important role, the relationship between the surgeon-anaesthesiologist dyad, who 'sometimes share, yield or compete for leadership', most critically influences overall OR team performance. ${ }^{19}$ Research has identified tension between anaesthesiologists and surgeons as potentially arising from misperceptions of each other and discrepant views on which their quality of collaboration and communication was built. ${ }^{19-24}$ Though power struggles in the OR have often been attributed to differences in professional training or values, ${ }^{15}$ research increasingly suggests that sex (ie, biological, anatomical and physiological characteristics) and gender (ie, identity, 
behaviour, roles and relations) shape team interactions in healthcare, as well as the different practice patterns observed among female and male physicians. ${ }^{25-34}$

Cohesive teamwork and effective communication are especially important in the cardiac OR given the high acuity of cases, frequent and sudden events of haemodynamic instability, critical moments of cardiopulmonary bypass initiation and separation, and the need for precise blood pressure control during key stages of operation. Moreover, the high-risk nature of cardiac surgery makes effective teamwork and communication even more critical in this operative setting. The predominance of male physicians in the cardiac OR compared with other surgical specialties ${ }^{35}$ may carry implications for operative communication and teamwork related to gendered hiearchies. For example, studies on non-cardiac OR teams show that female staff anaesthsiologists are challenged more often by the respiratory therapist than their male colleagues when an incorrect clinical decision is made. ${ }^{32} 34$ This suggests that there are implicit gender hierarchies within the $\mathrm{OR}$ and a potential reduction in the professional hierarchy gradient associated with female leadership. Another study found that if the attending surgeon's gender differed from the primary gender composition of the overall surgical team, cooperation increased and conflict decreased. ${ }^{33}$ Specifically, cooperation and communication were observed to decrease when more than half of the providers in an OR were male. ${ }^{33}$ The highest percentage of conflict interactions was observed in the cardiothoracic OR, where over $95 \%$ of staff surgeons were male. ${ }^{33}$ With increasing gender diversity in surgery, however, it is likely that team dynamics will also evolve.

Sex and gender may also be relevant to the performance of individual physicians in the cardiac OR. Recent findings also suggest that male anaesthesiologists spend a greater proportion of time and may thus be more experienced with the care of complex cardiac and/or vascular patients than their female counterparts. ${ }^{36}$ This remains true despite the increasing number of female providers entering the specialty.

Although physician's sex and gender have been shown to influence processes of care and outcomes in noncardiac medical and surgical care as well as in primary cardiac care, ${ }^{25} 26^{37-42}$ the role of these factors within the cardiac OR remains unclear. As such, it is necessary to quantify the effect of physician's sex and gender on clinical processes of care and adverse patient outcomes for the cardiac OR. To this end, we conducted a systematic review to analyse the role of anaesthesiologists' and surgeons' sex and gender in relation to processes of care and/or clinical outcomes within the context of cardiac operative care.

\section{METHODS}

This review was conducted and reported in accordance to the Preferred Reporting Items for Systematic Reviews and
Meta-Analyses (PRISMA).$^{43}$ The protocol was published in the University of Ottawa's research repository. ${ }^{44}$

\section{Eligibility criteria}

Studies were included if they involved surgical patients of any age who underwent a cardiac surgical procedure requiring anaesthetic care, as long as there were specific investigations on the impact of medical provider's (eg, cardiac surgeon and cardiac anaesthesiologist) sex and/or gender on primary outcomes of process of care or patient outcome. Processes of care include but are not limited to hemostatic practices, antibiotic prophylaxis, selection of coronary artery bypass conduits and harvesting of these conduits (ie, pedicled vs skeletonised). Patient perioperative outcomes include postoperative 30-day mortality and complications (eg, chylothorax, sternal wound infection, acute kidney injury, venous thrombosis, stroke, improvement of left ventricular function, blood loss and length of hospital stay). Studies that did not specifically investigate the impact of provider's sex/gender on process of care within the cardiac OR or patient outcomes, or that focused on patient's sex/gender differences without considering provider's sex/gender, were excluded. Studies that explored the implications of surgeon sex and/or gender in a variety of surgical specialties met inclusion criteria as long as cardiac procedures were included. Both comparative interventional (eg, randomised control trials) and non-interventional (eg, cohort) studies of any design were eligible for inclusion if they were published in a peer-reviewed journal. Letters, editorials, opinion pieces, conference abstracts and reviews were excluded. Grey literature produced outside of conventional scientific publishing and distribution was not considered for this review.

\section{Search strategy and information sources}

The search strategy was developed in collaboration with an experienced information specialist (Alexandra Davis) (online supplemental appendix 1). The strategy was then reviewed by a second information specialist as per Peer Review of Electronic Search Strategies guidelines. ${ }^{45}$ Searches were conducted in the electronic databases PsycINFO, Embase, Medline and Medline in Process (via OVID) from inception to 6 September 2018. Date and language restrictions were not applied; however, we planned to extract data from only those studies published in English or French. We also planned to search reference lists of included articles and to submit the final list of included studies to a group of experts (researchers, anaesthesiologists and surgeons involved in cardiac care) to verify relevance and accuracy.

\section{Study selection}

DistillerSR systematic review software (Evidence Partners, Ottawa, Canada) was used to facilitate the study screening and selection process. Screening forms were developed and piloted by members of the review team prior to undertaking full screening (AJ, FM, HS and KZ). Titles 
and abstracts were screened for eligibility in duplicate by two pairs of independent reviewers (AJ, FM, HS and KZ). The full texts of titles and abstracts deemed potentially relevant by two reviewers were then reviewed. At each level of screening, disagreements were resolved through consensus or discussion with a third reviewer, if necessary.

\section{Data items and abstraction}

Data abstraction was conducted in duplicate by two pairs of independent reviewers using an electronic form in DistillerSR. The form included publication details (eg, first author, year and country of data collection), clinical context (eg, type of procedure, type of anaesthesia and urgent or elective procedure), population demographics (eg, sex/gender of patients/ providers, patient comorbidities and patient age), study details (eg, research question/objective and methods used), outcomes assessed (ie, process of care or patient outcomes studied, definition and timing) and study results (ie, the reported impact of provider's/patient's sex/gender on process of care/ patient outcomes). To ensure that the study was inclusive of all eligible papers, we wanted to avoid limiting the inclusion criteria by outcomes defined a priori. Metaanalysis was not conducted, as it may not be suitable in capturing the breadth of the clinical outcomes that arise in eligible studies.

\section{Risk of bias}

The NIH Quality Assessment Tool for Observational Cohort and Cross-Sectional Studies was used to assess risk of bias. ${ }^{46}$ This tool includes 14 dichotomous items (ie, yes or no), such as clarity of the research question, specification of the study population, sample size justification and measurement of confounding variables. Studies are assigned a score of ' 1 ' if the criterion is present, for a total possible score of 14 (high quality). Reviewers assessed risk of bias independently and in duplicate, using consensus or third reviewer consultation to resolve disagreements (MD and FM).

\section{Patient and public involvement}

No patients were involved.

\section{RESULTS}

\section{Study selection}

The search yielded 3296 publications. After removal of duplicates, 2095 underwent title and abstract screening, and 2076 were removed due to failure to meet our eligibility criteria of assessing the impact of healthcare provider's sex/gender on processes of care and patient outcomes in the setting of cardiac surgery. Nineteen studies proceeded to full-text screening by satisfying the inclusion criteria on abstract screening or the abstract did not provide information to confidently be excluded without full-text review. After full-text review, 17 were excluded based on our predetermined inclusion and exclusion criteria. The study PRISMA flow diagram is shown in figure 1. A list of studies excluded at level 2 (with reasons) is provided in (online supplemental appendix 2).

\section{Study characteristics and synthesis}

There were two eligible English studies indirectly assessing the impact of healthcare provider's sex or gender in cardiac surgery in this systematic review. These studies are described below and summarised in table 1 .

An observational study by Tsugawa et $\mathrm{al}^{47}$ done in acute care hospitals across the USA evaluated the age and sex of surgeons on operative mortality of 892187 patients over 65 years of age undergoing 1 of 20 major non-elective surgeries from 2011 to 2014, 4 of which were common cardiovascular procedures (ie, carotid endarterectomy, heart valve procedures, coronary artery bypass grafting and abdominal aortic aneurysm repair). Among 45826 surgeons across the scope of surgical disciplines, 30-day mortality did not differ significantly between male $(n=41$ $192)$ and female ( $\mathrm{n}=4$ 634) surgeons (OR 0.97, 95\% CI 0.93 to 1.01). No sub-group analysis was conducted for cardiothoracic procedures.

A retrospective matched cohort study by Wallis et al ${ }^{29}$ explored the adverse postoperative outcomes (death, readmission or complications) among 104603 patients seen by female and male surgeons in Ontario, Canada, from 2007 to 2015, across 25 elective and non-elective procedures, including coronary artery bypass grafting. Overall, patients treated by female surgeons had a small but statistically significantly lower 30-day mortality (adjusted OR $0.88,95 \%$ CI 0.79 to $0.99, \mathrm{p}=0.04$ ) and comparable surgical outcomes (length of stay, complications and readmission), compared with those treated by male surgeons. Among patients of female $(n=4023)$ and male $(n=4039)$ cardiothoracic surgeons, there is weak evidence towards more favourable outcomes by female surgeons, with an OR of 0.91 (95\% CI 0.82 to 1.01) for postoperative adverse events.

\section{Risk of bias assessment}

The included studies were evaluated using the NIH Quality Assessment Tool for Observational Cohort and Cross-Sectional Studies. The overall quality rating for the internal validity of each study was relatively high (table 2). Both studies mitigated risk of bias by having a well-defined research question, pre-specified eligibility criteria, justified duration of follow-up, consideration for key confounding variables and insignificant loss to follow-up, among others. Two deductions in quality rating were due to the inability in examining different levels of exposure as related to the outcome and in assessing exposure more than once over time, as gender was determined to be binary and fixed in both studies. Tsugawa $e t$ al received an additional quality rating deduction for failure to provide sample size justification, power description, or variance and effect estimates. Detailed ratings for each study can be found in online supplemental appendix 3 . 


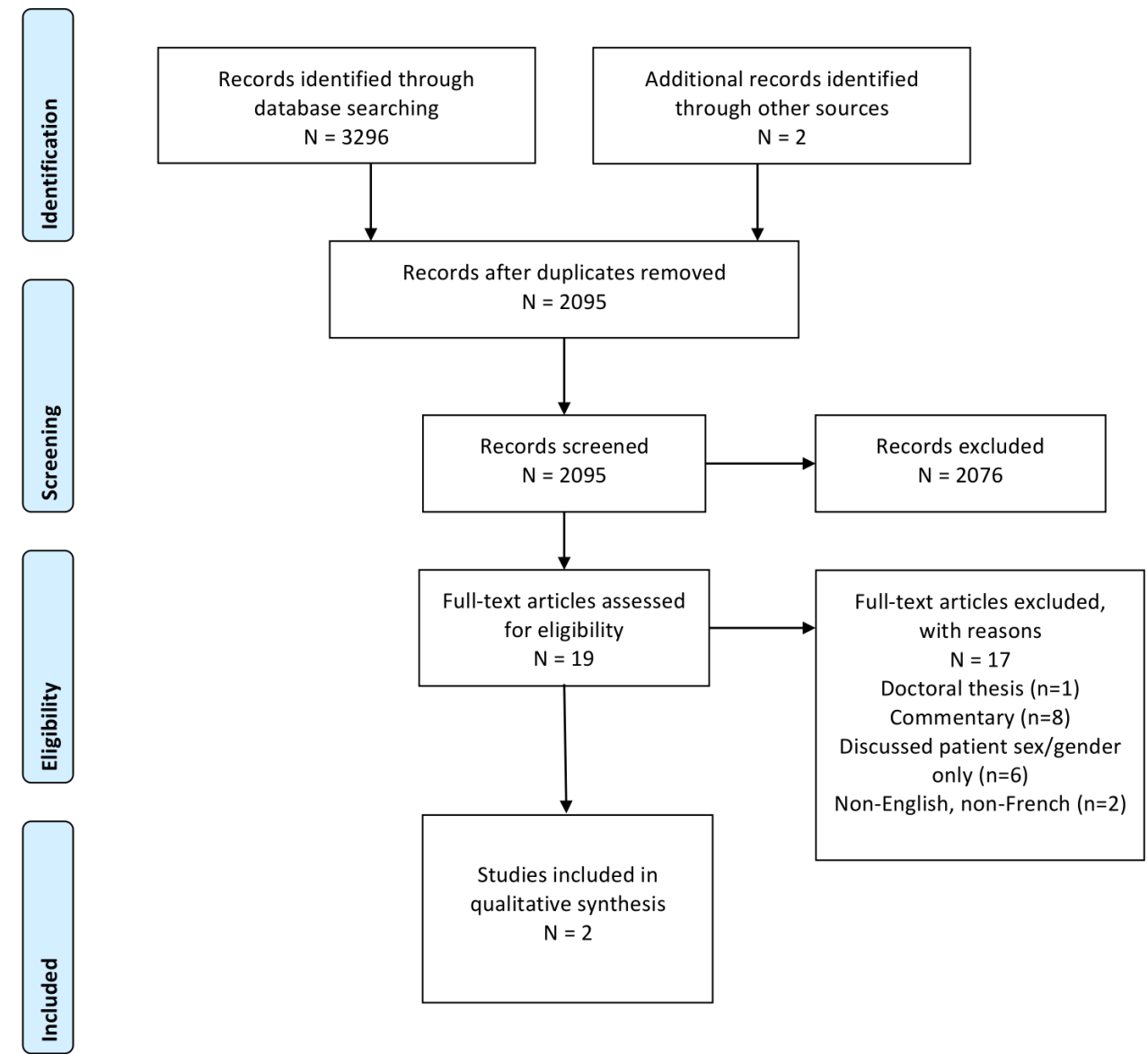

Figure 1 Preferred Reporting Items for Systematic Reviews and Meta-Analyses flow diagram.

\section{DISCUSSION}

\section{Summary of main results}

The novelty of this systematic review lies in its aim to assess the impact of both anaesthesiologists' and surgeons' sex and/or gender on perioperative cardiac processes of care and/or clinical outcomes. Out of 2093 references that were initially screened, we identified two English articles that briefly refer to cardiac surgery in the discussion of this topic in surgical specialties at large. These articles referred only to the sex of surgeons but not to that of anaesthesiologists.

Our inclusion criteria pre-specified publications in English and French; however, we identified two articles published in other languages (one in Japanese and one in Spanish) that may be relevant. We screened the English-language abstract of the article published in Japanese ${ }^{48}$ which discusses the implications of coronary artery bypass grafting in female patients. The English language translation of the full Spanish article was provided by a scientific colleague who is a native Spanish speaker. This article discusses patient sex differences in valvular surgery outcomes. ${ }^{49}$ Neither of these foreign language articles made clear references to provider's sex or gender.

\section{Explanation of the findings}

Sex and gender are key determinants of healthcare practices and their outcomes, including in patients who undergo non-cardiac surgery. ${ }^{50-53}$ Two recently published observational studies ${ }^{29} 31$ remotely investigated patient outcomes between female and male cardiac surgeons; however, primary statistical analyses were conducted to include data across all surgical specialties. Tsugawa et $a l$ included Medicare beneficiaries over 65 years of age undergoing a variety of non-elective procedures. In this study, only $10.1 \%$ of surgeons were female and it is unclear how many specialised in cardiac surgery. ${ }^{47}$ Hence, sex and gender analysis may have been underpowered in the arena of cardiac surgery practices. Wallis et al provided greater generalisability by considering all adult patients undergoing 25 common elective and non-elective procedures, with complete tracking of mortality and postoperative complications. Interestingly, Wallis et al noted some degree of evidence (OR 0.91, 95\% CI 0.82 to 1.01) for superior composite outcome of postoperative death, readmission or complications in patients under the care of female cardiothoracic surgeons compared with male cardiothoracic surgeons. They attributed this finding to female surgeons' tendency to adhere to guidelines, provide patient-centred care and attention to communication and teamwork. ${ }^{54}{ }^{55}$ Alternatively, this observation could also be explained by effect modification, as female surgeons were more heavily involved elective surgeries, which were in themselves associated better postoperative 


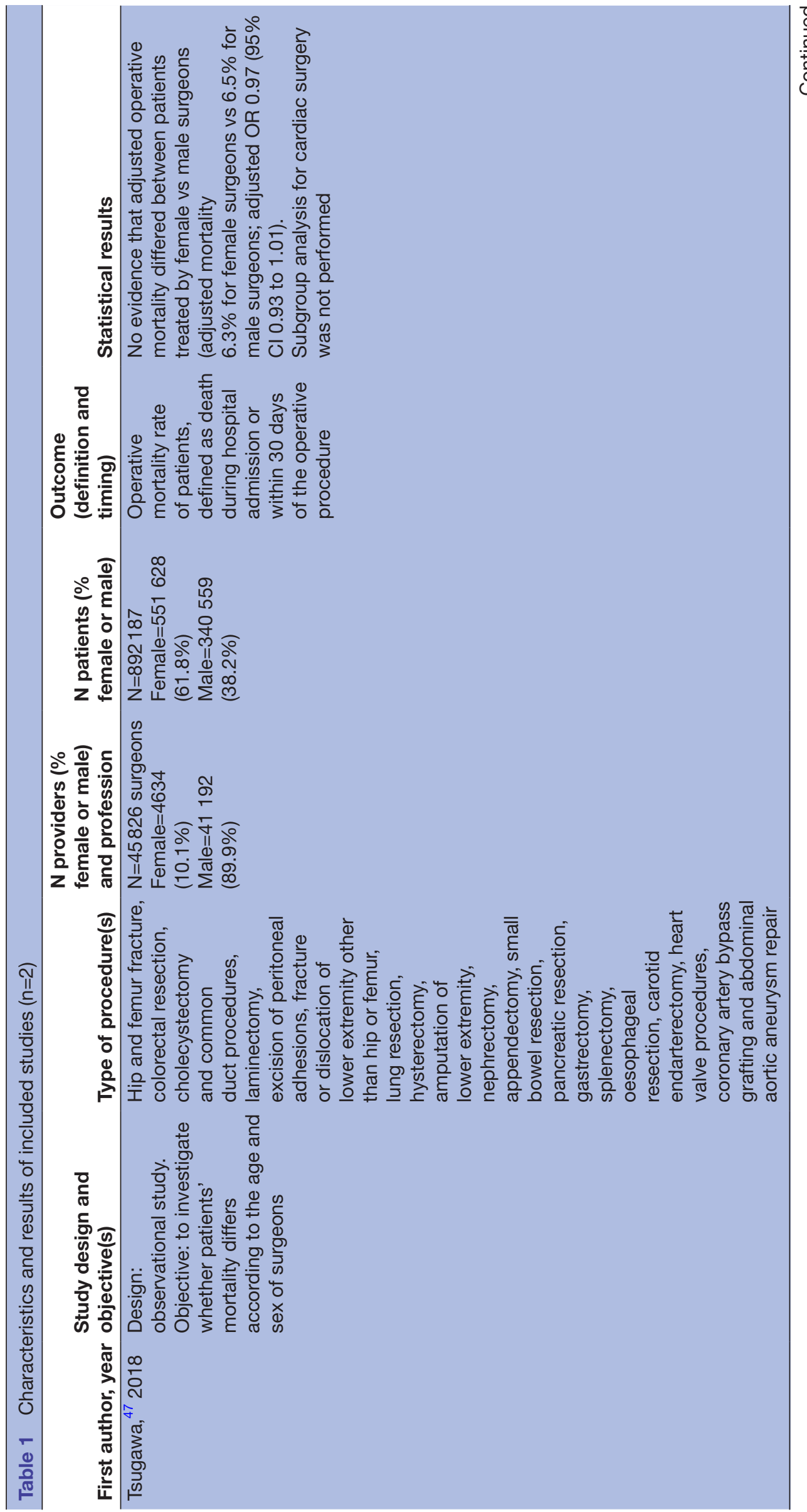




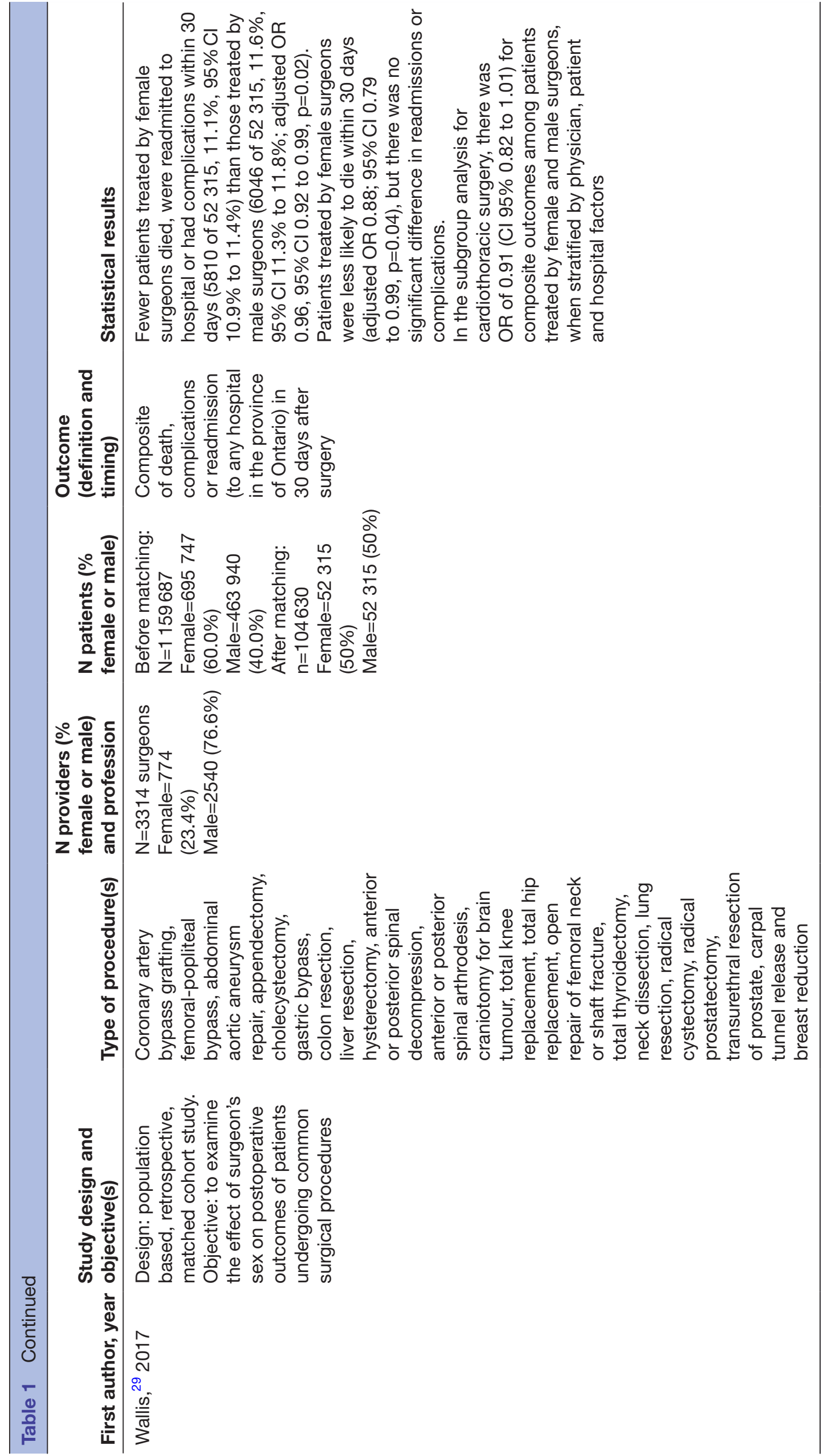


Table 2 Risk of bias for included studies: NIH Quality Assessment Tool for Observational Cohort and CrossSectional Studies

\begin{tabular}{ll}
\hline First author, year & Quality rating (/14) \\
\hline Tsugawa $^{47} 2018$ & 11 \\
Wallis $^{29}{ }^{2017}$ & 12 \\
\hline
\end{tabular}

outcomes as compared with urgent or emergent procedures. ${ }^{29}$ Overall, the study by Tsugawa and colleagues did not provide subgroup analysis for cardiac surgery, while both the Tsugawa and Wallis studies failed to specify the proportion of male and female surgeons within each specialty. These studies were also limited by shorter lengths of postoperative follow-up (ie, 30 days), as well as unmeasured confounders such as complexity of the operation and underlying disease severity.

Anaesthesiologist's sex was not considered in either studies. The fact that there are no published studies that explicitly explore the impact of physician's sex and gender for both surgeons and anaesthesiologists in the context of cardiac surgery was an unexpected finding. Given the high-stake nature of cardiac surgery and the crucial importance of teamwork in this context, our finding draws attention to potentially missed opportunities to optimise team and individual performance, as well as patient outcomes. Growing evidence in cardiac medical care and in non-cardiac surgery has shown that physicians' sex and gender significantly impact care. For example, OR teamwork is integral to preventing and treating many intraoperative and postoperative complications and can also be shaped by the sex composition of the team as well as gender roles and norms. ${ }^{11} 56$ In addition, there is considerable imbalance of physician's sex in cardiac surgery as compared with other surgical specialties, such that cardiac surgery has traditionally been viewed as a field dominated by male physicians. ${ }^{35}$ Therefore, an in-depth understanding of how physician's sex and gender influence team dynamics, in addition to individual performance, may inform future team-based interventions and ultimately mitigate preventable adverse events in cardiac surgery. ${ }^{57-60}$ Research in this domain might also inform an integrated clinical practice approach that moves beyond medical knowledge and experience, to individual and social factors. For example, educational interventions could be tailored based on provider's sex or cardiac OR scheduling apps could be designed to optimise OR team sex composition. Such an approach will shift the paradigm in patient safety research towards the personalisation of provider's characteristics, to provide all-around personalised medical care.

\section{Future directions}

Future research should consider physician's sex and gender when examining physician-related factors influencing surgical cardiac care. At minimum, studies should report the sex and/or gender characteristics of both the healthcare providers and patients involved so that future meta-analyses may be possible. ${ }^{61}$ In addition, sex and gender are not the only physician characteristics relevant to performance and their salience may depend on other factors such as age, level of experience, region of training or cultural background. ${ }^{62-65}$ Thus, studies that integrate sex and gender variables may also consider how they intersect with additional categories of social identity. Attention to anaesthesiologist's sex/gender, in particular, would be warranted given the lack of literature in this area in addition to the potential interaction between anaesthesiologist and surgeon sex/gender.

\section{Limitations of the study}

While this review has identified a critical knowledge gap in cardiac surgical care, there are some limitations of this review that are to be noted. First, we included only studies published in English or French. Two other non-English/ French studies were identified and were determined not to be relevant. Second, it is possible that studies examined physician's sex and/or gender as control variables but may have been excluded during title and abstract screening based on the failure of the study to specify this as a primary aim. Given our findings, combined with other systematic reviews showing the paucity of sex/gender analyses in medicine ${ }^{66}$ we believe it is unlikely that any relevant studies were missed by our search strategy or screening process.

Neither of the two studies included in this review specifically explored the impact of surgeon's and anaesthesiologist's sex or gender in the context of cardiac surgery in detail, nor did they include the processes of care as an outcome. Furthermore, the magnitude of reduction in adverse events and the methodology of propensity score matching used was at times unclear within the two observational studies presented in this review. ${ }^{29} 31$

\section{CONCLUSIONS}

This systematic review found no English or French language publication directly assessing the role of physician's sex and/or gender in cardiac operative care. Two observational studies investigated the impact of surgeon's sex on patient outcomes across the full scope of surgical specialties. These findings highlight the need for primary research to determine how these factors may influence cardiac surgical practice, in order to optimise provider's performance and improve outcomes in this high-risk patient group.

\section{Author affiliations}

${ }^{1}$ Clinical Epidemiology Program, Ottawa Hospital Research Institute, Ottawa, Ontario, Canada

${ }^{2}$ Department of Anaesthesiology and Pain Medicine, The Ottawa Hospital, Ottawa, Ontario, Canada

${ }^{3}$ School of Epidemiology and Public Health, Faculty of Medicine, University of Ottawa, Ottawa, Ontario, Canada

${ }^{4}$ Division of Cardiac Anesthesiology, Department of Anesthesiology and Pain Medicine, University of Ottawa Heart Institute, Ottawa, Ontario, Canada 
${ }^{5}$ Cardiovascular Research Program, Institute for Clinical Evaluative Sciences, Ottawa, Ontario, Canada

Correction notice This article has been corrected since it was published. Author name 'Cole Etherington' has been updated.

\section{Twitter Louise Y Sun @sunlouise1}

Acknowledgements We would like to thank Alexandra Davis, BA, MLIS, for her help in the development and review of the search strategies.

Contributors SB, CE, MD and LS: contributed substantially to conception and design, or analysis and interpretation of data, drafted the article, revised article critically for important intellectual content, gave final approval of the version to be published and agreed to act as guarantor of the work (ensuring that questions related to any part of the work are appropriately investigated and resolved). AJ, FM, HS and KZ: contributed substantially to acquisition of data, revised the article critically for important intellectual content, gave final approval of the version to be published and agreed to act as guarantor of the work (ensuring that questions related to any part of the work are appropriately investigated and resolved).

Funding This study was supported by University of Ottawa Heart Institute ORACLE Strategic Fund. SB was supported by the Ottawa Hospital Anaesthesia Alternate Funds Association. LS holds a Heart and Stroke Foundation of Canada National New Investigator Award, and is supported by a University of Ottawa Tier 2 Clinical Research Chair in Big Data and Cardiovascular Outcomes and the Ottawa Heart Institute Research Corporation. DistillerSR licenses were funded by the Department of Anesthesiology and Pain Medicine of the Ottawa Hospital.

Competing interests None declared.

Patient and public involvement Patients and/or the public were not involved in the design, or conduct, or reporting, or dissemination plans of this research.

Patient consent for publication Not required.

Provenance and peer review Not commissioned; externally peer reviewed.

Open access This is an open access article distributed in accordance with the Creative Commons Attribution Non Commercial (CC BY-NC 4.0) license, which permits others to distribute, remix, adapt, build upon this work non-commercially, and license their derivative works on different terms, provided the original work is properly cited, appropriate credit is given, any changes made indicated, and the use is non-commercial. See: http://creativecommons.org/licenses/by-nc/4.0/.

\section{ORCID iDs}

Cole Etherington http://orcid.org/0000-0002-7933-4593

Amy Johnston http://orcid.org/0000-0003-1934-7867

Katina Zheng http://orcid.org/0000-0003-3004-156X

Louise Y Sun http://orcid.org/0000-0003-3381-3115

\section{REFERENCES}

$1 \mathrm{Hu}$ J, Chen R, Liu S, et al. Global incidence and outcomes of adult patients with acute kidney injury after cardiac surgery: a systematic review and meta-analysis. J Cardiothorac Vasc Anesth 2016;30:82-9.

2 Crawford TC, Magruder JT, Grimm JC, et al. Complications after cardiac operations: all are not created equal. Ann Thorac Surg 2017;103:32-40.

3 Ontario C. Report on adult cardiac surgery: isolated coronary artery bypass graft (CABG) surgery,Isolated Aortic Valve Replacement (AVR) Surgery and Combined CABG and AVR Surgery October 2011 March 2016, 2018: 416-512.

4 Sun LY, Chung AM, Farkouh ME, et al. Defining an intraoperative hypotension threshold in association with stroke in cardiac surgery. Anesthesiology 2018;129:440-7.

5 Sun LY, Tu JV, Bader Eddeen A, et al. Prevalence and long-term survival after coronary artery bypass grafting in women and men with heart failure and preserved versus reduced ejection fraction. J Am Heart Assoc 2018;7:1-14.

6 Ma J-G, An J-X. Deep sternal wound infection after cardiac surgery: a comparison of three different wound infection types and an analysis of antibiotic resistance. J Thorac Dis 2018;10:377-87.

7 Fann JI, Moffatt-Bruce SD, DiMaio JM, et al. Human factors and human nature in cardiothoracic surgery. Ann Thorac Surg 2016;101:2059-66.

8 Baker DP, Day R, Salas E. Teamwork as an essential component of high-reliability organizations. Health Serv Res 2006;41:1576-98.
9 Gawande AA, Zinner MJ, Studdert DM, et al. Analysis of errors reported by surgeons at three teaching hospitals. Surgery 2003;133:614-21.

10 Hull L, Arora S, Aggarwal R, et al. The impact of nontechnical skills on technical performance in surgery: a systematic review. J Am Coll Surg 2012;214:214-30.

11 Mazzocco K, Petitti DB, Fong KT, et al. Surgical team behaviors and patient outcomes. Am J Surg 2009;197:678-85.

12 McCulloch P, Mishra A, Handa A, et al. The effects of aviation-style non-technical skills training on technical performance and outcome in the operating theatre. Qual Saf Health Care 2009;18:109-15.

13 Neily J, Mills PD, Young-Xu Y, et al. Association between implementation of a medical team training program and surgical mortality. JAMA 2010;304:1693-700.

14 Zegers M, de Bruijne MC, de Keizer B, et al. The incidence, rootcauses, and outcomes of adverse events in surgical units: implication for potential prevention strategies. Patient Saf Surg 2011;5:13.

15 Merry AF, Weller J, Mitchell SJ. Teamwork, communication, formulaone racing and the outcomes of cardiac surgery. $J$ Extra Corpor Technol 2014:46:7-14.

16 Schraagen JM, Schouten T, Smit M, et al. Assessing and improving teamwork in cardiac surgery. Qual Saf Health Care 2010;19:e29.

17 Welp A, Manser T. Integrating teamwork, clinician occupational wellbeing and patient safety - development of a conceptual framework based on a systematic review. BMC Health Serv Res 2016;16:281.

18 Goh SC, Chan C, Kuziemsky C, et al. Teamwork, organizational learning, patient safety and job outcomes. Int $J$ Health Care Qual Assur 2013;26:420-32.

19 Cooper JB. Critical role of the surgeon-anesthesiologist relationship for patient safety. Anesthesiology 2018;129:402-5.

20 Makary MA, Sexton JB, Freischlag JA, et al. Operating room teamwork among physicians and nurses: teamwork in the eye of the beholder. J Am Coll Surg 2006;202:746-52.

21 Pimentel MPT, Choi S, Fiumara K. Safety culture in the operating room: variability among perioperative healthcare workers. J patient SAF, 2017. Available: http://ovidsp.ovid.com/ovidweb.cgi?T=JS\& $\mathrm{PAGE}=$ reference\&D=medp\&NEWS=N\&AN=28574955 [Accessed 01 Jun 2017].

22 Wauben LSGL, Dekker-van Doorn CM, van Wijngaarden JDH, et al Discrepant perceptions of communication, teamwork and situation awareness among surgical team members. Int J Qual Health Care 2011;23:159-66.

23 Marsteller JA, Wen M, Hsu Y-J, et al. Safety culture in cardiac surgical teams: data from five programs and national surgical comparison. Ann Thorac Surg 2015;100:2182-9.

24 Cruz SA, Idowu O, Ho A, et al. Differing perceptions of preoperative communication among surgical team members. Am J Surg 2019;217:1-6.

25 Etherington $\mathrm{N}$, Boet $\mathrm{S}$. Why gender matters in the operating room: recommendations for a research agenda. $\mathrm{Br} J$ Anaesth 2018;121:997-9.

26 Tsugawa Y, Jena AB, Figueroa JF, et al. Comparison of hospital mortality and readmission rates for Medicare patients treated by male vs female physicians. JAMA Intern Med 2016;02138:1-8.

27 Ali A, Subhi Y, Ringsted C, et al. Gender differences in the acquisition of surgical skills: a systematic review. Surg Endosc 2015;29:3065-73.

28 Meyerson SL, Sternbach JM, Zwischenberger JB, et al. The effect of gender on resident autonomy in the operating room. J Surg Educ.

29 Wallis CJ, Ravi B, Coburn N, et al. Comparison of postoperative outcomes among patients treated by male and female surgeons: a population based matched cohort study. BMJ 2017;359:j4366.

30 Sharoky CE, Sellers MM, Keele LJ, et al. Does surgeon sex matter?: practice patterns and outcomes of female and male surgeons. Ann Surg 2017;XX:1-8.

31 Sarsons $\mathrm{H}$, Akhtari M, Barron $\mathrm{K}$, et al. Interpreting signals in the labor market: evidence from medical referrals, 2017. Available: https:// scholar.harvard.edu/files/sarsons/files/sarsons_jmp.pdf [Accessed 11 Dec 2017].

32 Amacher SA, Schumacher C, Legeret C, et al. Influence of gender on the performance of cardiopulmonary rescue teams. Crit Care Med 2017;45:1184-91.

33 Jones LK, Jennings BM, Higgins MK, et al. Ethological observations of social behavior in the operating room. Proc Natl Acad Sci 2018;201716883.

34 Pattni N, Bould MD, Hayter MA, et al. Gender, power and leadership: the effect of a superior's gender on respiratory therapists' ability to challenge leadership during a life-threatening emergency. $\mathrm{Br} J$ Anaesth 2017;119:697-702.

35 Canadian Medical Association. Cardiovascular / thoracic surgery profile.Ottawa, 2018. Available: https://cma.ca/sites/default/files/ 2019-01/cardiothoracic-surgery-e.pdf 
36 Baird M, Daugherty L, Kumar KB, et al. Regional and gender differences and trends in the anesthesiologist workforce. Anesthesiology 2015;123:997-1012.

37 Hamberg K, Risberg G, Johansson EE. Male and female physicians show different patterns of gender bias: a paper-case study of management of irritable bowel syndrome. Scand J Public Health 2004;32:144-52.

38 Jerant A, Bertakis KD, Fenton JJ, et al. Gender of physician as the usual source of care and patient health care utilization and mortality. J Am Board Fam Med 2013;26:138-48.

39 Fowler RA, Sabur N, Li P, et al. Sex-and age-based differences in the delivery and outcomes of critical care. CMAJ 2007;177:1513-9.

40 Curtis LH, Al-Khatib SM, Shea AM, et al. Sex differences in the use of implantable cardioverter-defibrillators for primary and secondary prevention of sudden cardiac death. JAMA 2007;298:2158-63.

41 Kaul P, Chang W-C, Westerhout CM, et al. Differences in admission rates and outcomes between men and women presenting to emergency departments with coronary syndromes. CMAJ 2007;177:1193-9.

42 Vaccarino V, Rathore SS, Wenger NK, et al. Sex and racial differences in the management of acute myocardial infarction, 1994 through 2002. N Engl J Med 2005;353:671-82.

43 Moher D, Liberati A, Tetzlaff J, et al. Reprint--preferred reporting items for systematic reviews and meta-analyses: the PRISMA statement. Phys Ther 2009;89:873-80.

44 Etherington N, Boet S, Deng M, et al. Physician sex, gender, processes of care, and clinical outcomes in perioperative cardiothoracic care: a systematic review protocol, 2018. Available: https://ruor.uottawa.ca/handle/10393/38897 [Accessed 13 Aug 2019].

45 McGowan J, Sampson M, Lefebvre C. An evidence based checklist for the peer review of electronic search strategies (press EBC). Evid Based Libr Inf Pract 2010;5:149.

46 National Heart, Lung and $\mathrm{BI}$ (NHLBI). Study quality assessment tools, 2018. Available: https://www.nhlbi.nih.gov/health-topics/studyquality-assessment-tools [Accessed 8 Aug 2018].

47 Tsugawa Y, Jena AB, Orav EJ, et al. Age and sex of surgeons and mortality of older surgical patients: observational study. BMJ 2018;361:k1343.

48 Kobayashi H, Kitamura S, Oyama C, et al. [Coronary artery bypass grafting in women: analyses of preoperative and intraoperative factors]. Nihon Kyobu Geka Gakkai Zasshi 1988;36:1285-91.

49 Vallejo JL, González Santos JM, Bastida E, et al. [Influence of sex in the technique and results of valvular surgery]. Rev Esp Cardiol 1994;47 Suppl 3:68-75.
50 Tannenbaum C, Greaves L, Graham ID. Why sex and gender matter in implementation research. BMC Med Res Methodol 2016;16:145.

51 Denton M, Prus S, Walters V. Gender differences in health: a Canadian study of the psychosocial, structural and behavioural determinants of health. Soc Sci Med 2004;58:2585-600.

52 Day S, Mason R, Lagosky S, et al. Integrating and evaluating sex and gender in health research. Health Res Policy Syst 2016;14:75.

53 Hankivsky O, Doyal L, Einstein G, et al. The odd couple: using biomedical and intersectional approaches to address health inequities. Glob Health Action 2017;10:1326686.

54 Frank E, Dresner $\mathrm{Y}$, Shani $\mathrm{M}$, et al. The association between physicians' and patients' preventive health practices. CMAJ 2013;185:649-53.

55 Lurie N, Slater J, McGovern P, et al. Preventive care for women. does the sex of the physician matter? $N$ Engl J Med 1993;329:478-82.

56 The Joint Commission. Sentinel event data: root causes by event type 2004-2015, 2016.

57 Ostlin P, Eckermann E, Mishra US, et al. Gender and health promotion: a multisectoral policy approach. Health Promot Int 2006;21 Suppl 1:25-35.

58 Keleher $\mathrm{H}$. Why build a health promotion evidence base about gender? Health Promot Int 2004:19:277-9.

59 Lewis MA, Neighbors C. Optimizing personalized normative feedback: the use of gender-specific referents. J Stud Alcohol Drugs 2007;68:228-37.

60 Simen-Kapeu A, Veugelers PJ. Should public health interventions aimed at reducing childhood overweight and obesity be genderfocused? BMC Public Health 2010;10:1-7.

61 Clayton JA, Tannenbaum C. Reporting sex, gender, or both in clinical research? JAMA 2016;316:1863-4.

62 Li C-J, Syue Y-J, Tsai T-C, et al. The impact of emergency physician seniority on clinical efficiency, emergency department resource use, patient outcomes, and disposition accuracy. Medicine 2016;95:e2706.

63 Moy E, Bartman BA. Physician race and care of minority and medically indigent patients. JAMA 1995;273:1515.

64 Roetzheim RG, Fox SA, Leake B. Physician-reported determinants of screening mammography in older women: the impact of physician and practice characteristics. J Am Geriatr Soc 1995;43:1398-402.

65 Aiken LH, Dahlerbruch JH. Physician age and patient outcomes. BMJ 2017;357:j2286.

66 Phillips SP, Hamberg K. Doubly blind: a systematic review of gender in randomised controlled trials. Glob Health Action 2016;9:29597. 